\title{
Amblyopia among African pupils in Rwanda
}

\author{
Y. YASSUR, S. YASSUR, S. ZAIFRANI, U. SAGHS, AND \\ I. BEN-SIRA \\ Department of Ophthalmology, Hadassah Medical Centre, Jerusalem, Israel
}

The prevalence of amblyopia in developing African countries has not yet been studied systematically. This report is a result of a pilot study of the prevalence of amblyopia among school children in Rwanda, a country located in the centre of the African highlands close to the equator.

\section{Material and methods}

A random sample consisting of 1,550 pupils ( 1,130 boys and 420 girls) aged 10 to 18 years from six schools in the two main cities of Rwanda was examined.

The preliminary examination, which was performed at school, consisted of measurement of the visual acuity of each eye on a Snellen chart, followed by an external examination of the eyes. Those in whom the visual acuity was found to be 6/12 or less in at least one eye were referred to the University Hospital Eye Clinic. When the visual acuity could not be improved by a simple subjective refraction, an examination was made with the slit lamp, fundoscope, retinoscope, and the cover and cover-uncover tests. Patients in whom the defective vision proved to be due to an organic eye disease were excluded from the survey.

\section{Results}

Table I shows that, of the I, $55^{\circ}$ pupils examined, eighteen $(\mathrm{I} \cdot 2$ per cent.) were unilaterally amblyopic.

Table II shows the types of deviation of the amblyopic eyes; five eyes showed no deviation, five were esotropic, and eight were exotropic.

Table I Prevalence of amblyopia among pupils examined

\begin{tabular}{lll}
\hline & \multicolumn{2}{c}{ Cases of amblyopia } \\
\cline { 2 - 3 } No. of pupils & No. & Percentage \\
\cline { 2 - 3 } $\mathrm{I}, 550$ & 18 & $1 \cdot 2$ \\
\hline
\end{tabular}

Table II Ocular deviations of amblyopic eyes

\begin{tabular}{llll}
\hline $\begin{array}{lll}\text { Type of ocular } \\
\text { deviation }\end{array}$ & & No. & Per cent. \\
\cline { 1 - 1 } Esotropia & & 5 & 28 \\
Exotropia & 8 & 44 \\
No heterotropia & 5 & 28 \\
\hline
\end{tabular}

Table III shows the relationship between the different refractive errors of the amblyopic eyes and the ocular deviation. Six subjects were myopic (between -2 and $-9 \mathrm{D}$ sph.), four were hypermetropic (between +2 and $+5 \mathrm{D}$ sph.), three were anisometropic with 
differences of more than 2 dioptres, two were astigmatic (both with myopic astigmatism of more than 2 dioptres), and three were emmetropic.

Table IV shows the visual acuity of the amblyopic eyes; two eyes were $6 / 12$, eight $6 / 18$ to $6 / 6 \mathrm{o}$, and eight eyes less than $6 / 6 \mathrm{o}$.

Table III Relationships between refractive errors of the amblyopic eyes and deviation (Percentage in brackets)

\begin{tabular}{|c|c|c|c|c|c|c|}
\hline \multirow{2}{*}{$\begin{array}{l}\text { Type of } \\
\text { ocular } \\
\text { deviation }\end{array}$} & \multirow{2}{*}{ No. of cases } & \multicolumn{5}{|l|}{ Refractive error } \\
\hline & & Hypermetropia & Myopia & Anisometropia & Astigmatism & Emmetropia \\
\hline Esotropia & $5(28)$ & $4(23)$ & & & $\mathbf{I}$ & \\
\hline Exotropia & $8(44)$ & & 4 & $\mathbf{I}$ & I & 2 \\
\hline No heterotropia & $5(28)$ & & 2 & 2 & & $\mathbf{I}$ \\
\hline Total & $18(100)$ & 4(23) & $6(33)$ & $3(16)$ & $2(12)$ & $3(16)$ \\
\hline
\end{tabular}

Table IV Visual acuity of amblyopic eyes (Percentages in brackets)

\begin{tabular}{llll}
\hline Visual acuity & $\frac{6 / 12}{2(12)}$ & $\frac{6 / 18-6 / 60}{8(44)}$ & $\frac{\text { Less than 6/60 }}{8(44)}$ \\
\hline
\end{tabular}

\section{Discussion}

No data of the rates of amblyopia in African countries are available. Reports from nonAfrican countries show varying prevalences of amblyopia ranging from $I \cdot 0$ to 5.3 per cent., but different criteria for amblyopia were used (Table V).

Table $\mathbf{V}$ Prevalence of amblyopia reported by various authors (Flom and Neumaier, I966)

\begin{tabular}{|c|c|c|c|}
\hline Author & Date & $\begin{array}{l}\text { Percentage } \\
\text { amblyopia }\end{array}$ & $\begin{array}{l}\text { Limit of normal } \\
\text { visual acuity }\end{array}$ \\
\hline Theodor & I 944 & $4 \cdot 0$ & $20 / 50$ \\
\hline Agalston & 1944 & $1 \cdot 8$ & $20 / 40$ \\
\hline Glower and Braver & I944 & $2 \cdot 4$ & $20 / 70$ \\
\hline Downing & 1945 & $3 \cdot 2$ & \\
\hline De Röth & 1945 & $4 \cdot 5$ & $20 / 50$ \\
\hline Mc.Neil & 1955 & $2 \cdot 7$ & $20 / 30$ \\
\hline Cole & 1959 & $5 \cdot 3$ & $20 / 40$ \\
\hline Russel and others & $196 \mathrm{I}$ & $1 \cdot 3$ & \\
\hline Cholst and others & 1962 & $4 \cdot 7$ & \\
\hline Helveston & I965 & $I \cdot 0$ & $20 / 50$ \\
\hline Flom and Neumaier & I 966 & $1 \cdot 0$ & \\
\hline Oliver and Nawratzki & 1971 & $1 \cdot 2$ & \\
\hline
\end{tabular}


Our survey was carried out among fully cooperative pupils of io to I 8 years of age, and a visual acuity of $6 / 12$ or less was used as the criterion, so that the maximum rate of amblyopia was probably detected.

It is interesting to note the high rate of myopia (33 per cent.) in our survey, in contrast to that given in most of the other reports (Gansner, I968: 5 per cent.; Oliver and Nawratzki, I97 I : I4 per cent.). This corresponds to the high rate of myopia among the refractive errors found in Rwanda (Yassur and others, in preparation).

A prominent difference between the results of our survey and reports from non-African countries is the high rate (44 per cent.) of exotropia in the amblyopic eyes (Table VI).

Table VI Percentage ocular deviation associated with amblyopia reported by various authors

\begin{tabular}{|c|c|c|c|c|}
\hline Author & Downing & Helveston & $\begin{array}{l}\text { Oliver and } \\
\text { Nawratzki }\end{array}$ & $\begin{array}{l}\text { Yassur and } \\
\text { others }\end{array}$ \\
\hline Date & $1942-3$ & $1962-3$ & 1971 & 1972 \\
\hline Without strabismus & 45 & 52 & 38 & 28 \\
\hline With esotropia & 40 & 40 & 54 & 28 \\
\hline With exotropia & 15 & 8 & 8 & 44 \\
\hline
\end{tabular}

All the exotropic eyes were either myopic or emmetropic and none was hypermetropic. It is possible, therefore, that the high rate of exotropia can be attributed partly to the high rate of myopia and myopic astigmatism and partly to the age of the pupils examined, but there are probably other factors involved which have not yet been discovered.

\section{Summary}

A survey to detect amblyopia was carried out in I,550 African pupils in Rwanda. Eighteen ( $1 \cdot 2$ per cent.) were found to be unilaterally amblyopic (visual acuity 6/1 2 or less); eight of these were myopes (including myopic astigmats), four hypermetropes, three anisometropes, and three emmetropes. Of the eighteen amblyopic eyes, eight were exotropic and five esotropic, and five did not deviate. None of the exotropic eyes was hypermetropic.

The possible relationship between the amblyopia, type of ocular deviation, and refractive error s is discussed.

We are indebted to Prof. I. Nawratzki for her invaluable advice.

\section{References}

Downing, A. H. (I945) Arch. Ophthal. (Chicago), 33, I 37

flom, M. C., and Neumaier, R. W. (ig66) Publ. Hlth Rep. (Wash.), 81, 329

GANSNER, J. (I968) Ophthalmologica (Basel), r55, 234

helves ron, E. M. (I965) Amer. 7. Ophthal., 6o, 75

oliver, M., and NAWratzki, I. (1971) Brit. J. Ophthal., 55, 462, 467 